Dicle University Journal of Engineering (DUJE)

web: http://dergipark.gov.tr/dumf

Araștırma Makalesi / Research Article

\title{
AISI 1040 çeliğinin tornalama-frezeleme ile işlenmesinde yüzey pürüzlülüğünün genetik algoritma yöntemi ile optimizasyonu
}

\section{Optimizing Surface Roughness Through the Genetic Algorithm Method in Machining of AISI 1040 steel by Turning-Milling}

\author{
Çetin Özay ${ }^{*}$ Zahide Küçük \\ ${ }^{1}$ Frrat Üniversitesi, Makine Mühendisliği Bölümü, Elazı̆̆, cozay@firat.edu.tr \\ ${ }^{2}$ Fırat Üniversitesi, Makine Mühendisliği Bölümü, Elazığ, zhdekucuk@gmail.com
}

\begin{tabular}{l} 
MAKALE BİLGILERİ \\
\hline Makale geçmişi: \\
Geliş: 5 Şubat 2020 \\
Düzeltme: 13 Mart 2020 \\
Kabul: 18 Mart 2020 \\
\hline Anahtar kelimeler: \\
Tornalama-frezeleme, yüzey \\
pürüzlülüğü, taguchi metodu, \\
genetik algoritma
\end{tabular}

\section{ÖZET}

Bu çalışmada Taguchi deney tasarım metodu kullanılarak AISI1040 malzemesinin ortagonal ve teğetsel tornalama-frezeleme yöntemleri ile işlenmesinde kesme parametrelerinin yüzey pürüzlülüğü üzerindeki etkileri incelenmiştir. Deneysel çalışmalarda işleme parametreleri olarak; işlem, kesici takım devri, iş parçası devri, talaş derinliği ve eksenel ilerleme parametreleri seçilmiştir. Deneysel çalışma sonuçları Minitab15 paket programı kullanılarak $\mathrm{S} / \mathrm{N}$ oranlarına dönüştürülüp optimum kesme parametreleri belirlenmiştir. ANOVA varyans analizi ile de istatistiksel olarak analiz edilmiştir. Yanıt yüzey yöntemi ile yüzey pürüzlülüğünün kesme parametrelerine bağlı olarak matematiksel modeli oluşturulmuştur. Ayrıca genetik algoritma yöntemi kullanılarak minimum yüzey pürüzlülügü için en uygun kesme parametre değerleri belirlenmiștir. Sonuç olarak, deneysel çalıșmalar, istatistiksel analiz ve optimizasyon işlemlerinde teğetsel tornalama-frezeleme işleminin yüzey pürüzlülüğünü azalttığ 1 belirlenmiştir. Genetik algoritma yöntemi, S/N oranları ve matematiksel modelden elde edilen minimum yüzey pürüzlülüğü değerlerinin birbirine çok yakın olduğu tespit edilmiștir.

Doi: $10.24012 /$ dumf. 685119

\begin{tabular}{l} 
ARTICLE INFO \\
\hline Article history: \\
Received: 5 February 2020 \\
Revised: 13 March 2020 \\
Accepted: 18 March 2020 \\
\hline Keywords: \\
Turning-milling, Surface Roughness,
\end{tabular}

Taguchi Method, Genetic Algorithm

\begin{abstract}
In this study, the effects of the cutting parameters on surface roughness in machining of AISI 1040 material through orthogonal and tangential turning-milling methods were investigated using the Taguchi experimental design method. The parameters of process, cutting tool speed, workpiece speed, cutting depth, and axial feed were selected as processing parameters in the experimental studies. The experimental results were converted to $\mathrm{S} / \mathrm{N}$ ratios using Minitab15 packaged software in order to determine the optimum cutting parameters. They then were statistically analyzed using ANOVA analysis of variance. Using the response surface method, a mathematical model of the surface roughness was created based on the cutting parameters. Additionally, the most suitable cutting parameter values were identified for minimum surface roughness by using the genetic algorithm method. The results revealed that the tangential turning-milling process reduced surface roughness in experimental studies, statistical analysis, and optimization processes. The minimum surface roughness values obtained from the genetic algorithm method, the $\mathrm{S} / \mathrm{N}$ ratios, and mathematical model were very close to each other.
\end{abstract}

* Sorumlu yazar / Correspondence

Çetin ÖZAY

$\bowtie$ cozay@firat.edu.tr 


\section{Giriș}

Gün geçtikçe CNC takım tezgâhlarında hassasiyet, verim, karmaşık yapılı parçaların işlenmesi ve işleme hızını artırma amacı ile farklı eksenler tanımlanmakta, farklı geometri ve işleve sahip kesici takımlar tasarlanmaktadır [1,2]. Tornalama- frezeleme yöntemleri de son yıllarda parça ve kesicilerin eş zamanlı hareket etmesine imkân sağlayan yöntemler olarak ortaya çıkmışlardır.

Verimlilik ve kalite yönünden çok kesen ağızlı takımlar daha fazla önem kazanmışlardır. Bu tür uygulamalar genellikle düzlemsel yüzeylere gerçekleştirilir. Tornalama işlemlerinde çok kesen ağılı takımlar kullanılarak benzer avantajların, özellikle yüksek miktarda talaş kaldırmanın [3], dönel yüzeyler için de elde edilmesi freze takımlarının kullanılmasıyla sağlanabilir. $\mathrm{Bu}$ bağlamda tornalama-frezeleme yönteminde kesici takım talaş kaldırma işlemi yaparken birden fazla ağız temas etmektedir, ayrıca kesici takım da döndüğü için iş parçası ve kesici takım ağızları arasında oluşan temas uzunluğu azalmaktadır. Bu azalmadan dolayı kesici takım ağzında oluşacak deformasyon gecikmekte ve oluşacak yüzey pürüzlülüğü de azalmaktadır. Pogacnik ve Kopac, tornalamafrezeleme yönteminde işleme parametrelerinin dinamik dengesizliğe olan etkilerini inceleyip tornalama yöntemiyle kıyaslamıştır. Yaptığ 1 çalışmada oluşan merkezkaç kuvvetini ve yüzey pürüzlülüğünde olan farklılığı araştırmıştır [4]. Kopac ve Pogacnik, tornalama-frezeleme işleminde kesici ile iş parçası konumunun ve titreşimin yüzey kalitesi üzerindeki etkisini teorik ve deneysel olarak incelemişlerdir [5]. Choudhury ve Bajpai, ortagonal tornalamafrezeleme yöntemindeki farklı kesme parametrelerinin yüzey pürüzlülüğü üzerindeki etkisini incelemişlerdir. Yaptıkları bu incelemeler sonucunda ortagonal tornalamafrezeleme yönteminin klasik frezeleme yöntemine kıyasla daha düşük yüzey pürüzlülüğü oluşturduğunu gözlemlemişlerdir [6]. Savaş ve Özay, genetik algoritma yöntemini kullanarak teğetsel tornalama-frezeleme yöntemindeki kesme parametrelerinin yüzey pürüzlülüğü üzerindeki etkisini araştırmış ve kesme parametrelerinin optimizasyonunu yapmışlardır. Çalışmalarında kesici takım ve iş parçası devrinin artırılmasının belirli bir değere kadar yüzey kalitesini arttırdığını, bu parametrelerin daha yüksek seçilmesi durumunda yüzey kalitesinin düştüğünü ifade etmişlerdir [7]. Lee, ve Chiou, tornalamafrezeleme yöntemi ile eş eksenli olmayan iş parçaları işlemişlerdir. $\mathrm{Bu}$ parçaların işlenmesinde uygun kesme şartlarını araştırmışlardır. Eş eksenli olamayan iş parçalarının işlenmesinde tornalama-frezeleme yönteminin tornalamaya göre daha üstün olduğunu belirtmişlerdir [8]. Karagüzel ve dĭ̆., Ortagonal, teğetsel ve eş eksenli tornalamafrezeleme yöntemlerinde kesme kuvvetlerini, daireselliği ve yüzey kalitesi sonuçlarını analitik ve deneysel olarak incelemiştirler. Elde ettikleri sonuçların oluşturulan analitik model sonuçları ile uyumlu olduğunu belirtmişlerdir [9]. Ratnam ve diğ., Ortagonal ve teğetsel tornalamafrezeleme yöntemlerini kullanarak, kesme parametrelerinin titreşim ve yüzey pürüzlülüğü üzerindeki etkilerini incelemişlerdir. Teğetsel tornalama-frezeleme yönteminin ortagonal yönteme göre daha iyi sonuçlar verdiğini belirtmişlerdir [10].

Talaşlı imalat sektöründe yapılan deneysel çalışmaların optimum parametrelerinin belirlenmesi amacı ile bazı metotlar kullanılarak matematiksel denklemler oluşturulmakta; optimizasyon programları yardımı ile de optimizasyon işlemi gerçekleştirilmektedir. Optimum parametrelerin belirlenmesi imalat hizı ve kalitesini artırmakta ayrica maliyeti düşürmektedir. Matematiksel denklemlerin oluşturulmasında yanıt yüzey metodu yaygın olarak kullanılmaktadır. Bu metot daha az deney sonucunu kullanarak parametrelerin sonuçla olan ilişkisini ortaya koyan bir denklem oluşturmaktadır. $\mathrm{Bu}$ denklem, yapılmamış deneylerde oluşabilecek sonuçların belirlenmesine imkan sağlamaktadır. Belirlenen bu uygunluk denklemi ve parametrelerin sinırları kullanılarak genetik algoritma yöntemi ile optimizasyon yapılmaktadır. Kılıçkap ve Hüseyinoğlu AISI 316 malzemesinin delinmesinde oluşan çapak yüksekliğini yanıt yüzey yöntemi kullanarak matematiksel 
modelini oluşturarak genetik algoritma metodu ile optimizasyonunu yapmışlardır. Yapılan çalışmada deneysel ve yanıt yüzey metodu ile elde edilen sonuçların birbiri ile uyumlu olduğunu belirlemişlerdir [11]. Senthilkumar ve diğ. 4140 çeliğinin derin kriyojenik işlemine tabi tutulmasında minimum aşınma kaybının belirlenmesi amacı ile Taguchi deney tasarım yöntemi kullanarak deney planını hazırlamışlardır. Yanıt yüzey metodu kullanılarak deney sonuçlarından matematiksel bir model oluşturup genetik algoritma yöntemi ile optimizasyonunu yapmışlardır. Deneysel çalışmalardan ve matematiksel modelden elde edilen sonuçların uyumlu olduğunu belirtmişlerdir [12].

Murat ve diğ. Yanıt yüzey metodu ve merkezi bileşik metodu kullanarak sertleştirilmiş soğuk iş takım çeliğinin tornalamasında kesme parametrelerinin takım aşınması üzerindeki etkilerini incelemişlerdir. Çalışma neticesinde elde edilen model ve deney sonuçlarının birbirini yakınsadığını belirtmişlerdir [13]. Savaş ve diğ. Taguchi deney tasarım metodu kullanarak 100Cr6 malzemesinin teğetsel tornalamafrezeleme yöntemi ile işlenmesinde kesme parametrelerinin yüzey pürüzlülüğü üzerindeki etkilerini incelemişlerdir. Genetik algoritma yöntemi ile de yüzey pürüzlülüğ̈̈nün optimizasyonu yapılmışlardır. Deneysel çalışmalar ve genetik algoritma sonuçlarının birine benzer sonuçlar verdiğini belirtmişlerdir [14]. Yağmur ve diğ. Taguchi deney tasarım yöntemi kullanarak AISI 1050 çelik malzemesini kaplamalı ve kaplamasız kesici takımlar kullanarak farklı kesme parametrelerinin itme kuvveti üzerindeki etkilerini araştırmışlardır. Uygulanan Taguchi yöntemi neticesinde, en uygun parametrenin kaplamalı takım için, kesme hiz1 $90 \mathrm{~m} /$ dak ve ilerleme hız ise $0,15 \mathrm{~mm} / \mathrm{dev}$ olarak belirlemişlerdir [15 ].

Yapılan literatür çalışmalarında tornalamafrezeleme yöntemlerinde kesme parametrelerinin yüzey pürüzlülüğü, titreşim ve dairesellik üzerindeki etkileri incelenmiştir. $\mathrm{Bu}$ çalıșmada amaç, taguchi deney tasarım metodu kullanılarak AISI 1040 iş parçasının ortagonal ve teğetsel tornalama-frezeleme yöntemleri ile işlenmesinde kesme parametrelerinin ortalama yüzey pürüzlülügü üzerindeki etkileri araştırmaktır. Elde dilen ortalama yüzey pürüzlülüğü değerleri $\mathrm{S} / \mathrm{N}$ oranlarına dönüştürülerek optimum parametre seviyeleri belirlenmesidir. Ayrıcı yanıt yüzey metodunda ortalama yüzey pürüzlülügünün matematiksel modeli oluşturularak genetik algoritma yöntemi ile optimizasyon işleminde optimum kesme parametrelerinin belirlenmesi amaçlanmıştır.

\section{Materyal ve Metot}

Bu çalışmada kullanım alanı çok geniş olan AISI 1040 malzemesi kullanılmıştır. AISI 1040 taşıt, motor, makine ve aparat yapımında orta zorlamalı parçalarda, cer kancaları, dişliler, miller ve kalıp setlerinde kullanılır. İş parçası boyu ISO 3685 ve TSE 10379 standartlarına göre Ø24x60 mm olarak hazırlanmıştır. Malzemenin mekanik özellikleri Tablo 1.'de, malzemenin kimyasal bileşimi Tablo 2.'de verilmiştir.

Tablo 1. AISI 1040 malzeme özellikleri

Table 1. AISI 1040 material properties

\begin{tabular}{cccccc}
\hline $\begin{array}{c}\text { Çekme } \\
\begin{array}{c}\text { Mukavemeti } \\
(\mathbf{M P a})\end{array}\end{array}$ & $\begin{array}{c}\text { Akma } \\
\text { Mukavemeti } \\
(\mathbf{M P a})\end{array}$ & $\begin{array}{c}\text { Kesme } \\
\text { Mukavemeti } \\
(\mathbf{M P a})\end{array}$ & $\begin{array}{c}\text { Elastiklik } \\
\text { Modülü } \\
(\mathbf{M P a})\end{array}$ & $\begin{array}{c}\text { Yüzde } \\
\text { Uzama } \\
(\boldsymbol{\%})\end{array}$ & $\begin{array}{c}\text { Sertlik } \\
(\mathbf{H B})\end{array}$ \\
\hline 600 & 361 & 410 & $190-210$ & 25 & 190 \\
\hline
\end{tabular}

Tablo 2. AISI 1040 malzemesinin kimyasal bileşimi (\%)

Table 2. Chemical composition of AISI 1040 material (\%)

\begin{tabular}{cccccccc}
\hline $\mathbf{C}$ & $\mathbf{S i}$ & Mn & P mak. & S mak. & Cr & Mo & N \\
\hline $0.40-0.50$ & $0.25-0.35$ & $0.60-0.90$ & 0.04 & 0.05 & - & - & - \\
\hline
\end{tabular}


Kesici takım olarak çapı Ø20 mm, uzunluğu 100 $\mathrm{mm}, 4$ ağızlı, helis açısı $30^{\circ}$, uç açısı $6^{\circ}$ olan HSS kullanılmıştır. Tornalama-frezeleme deneyleri CNC JOHNFORD WMC 850 FANUC OM dik işleme merkezli freze tezgâhında yapılmıştır. Şekil 1. 'de deneylerde kullanilan deney düzeneği ve eksenlerin paralelliğinin kontrol edilmesi gösterilmektedir. İş parçasının salgılı dönmesini önlemek amaciyla komparatör yardımıyla deney düzeneğinin paralelliği kontrol edilmiştir.

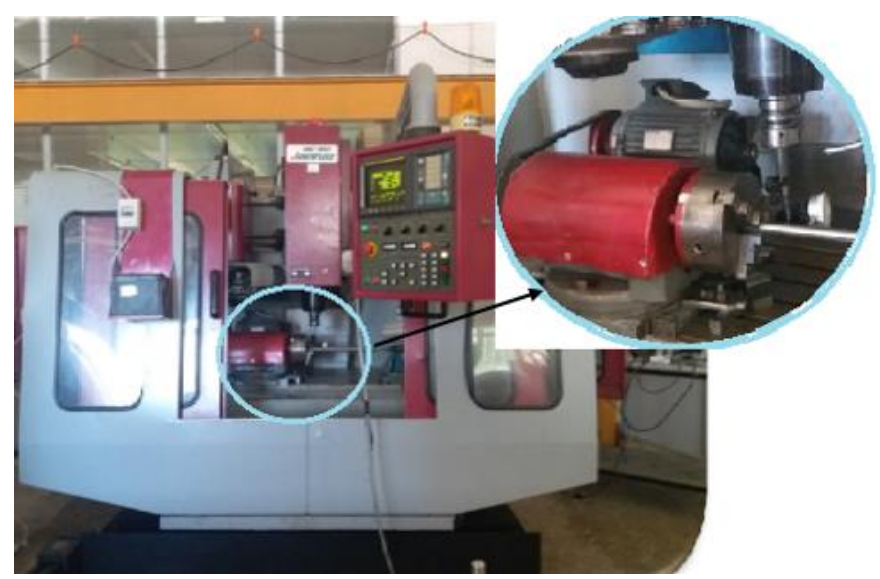

Figure 1. Tornalama-frezeleme deney düzeneği ve paralellik kontrolü Figure 1. Turning-milling test setup and parallelism control

Kesme parametreleri olarak Tablo 3. 'te verilen işlem, kesici takım devri, iş parçası devri, eksenel ilerleme hızı ve talaş derinliği kullanılmıştır. İşlem parametresi ortagonal tornalamafrezeleme yöntemi için 1 , teğetsel tornalamafrezeleme yöntemi için 2 sembolü seçilmiştir.
Şekil 2.'de de işleme yöntemleri gösterilmiştir. Şekil 2.(a)'da kesici takımın iş parçasına temas şekli teğetsel durumda iken Şekil 2.(b)'de ise ortagonal temas durumu gösterilmektedir.
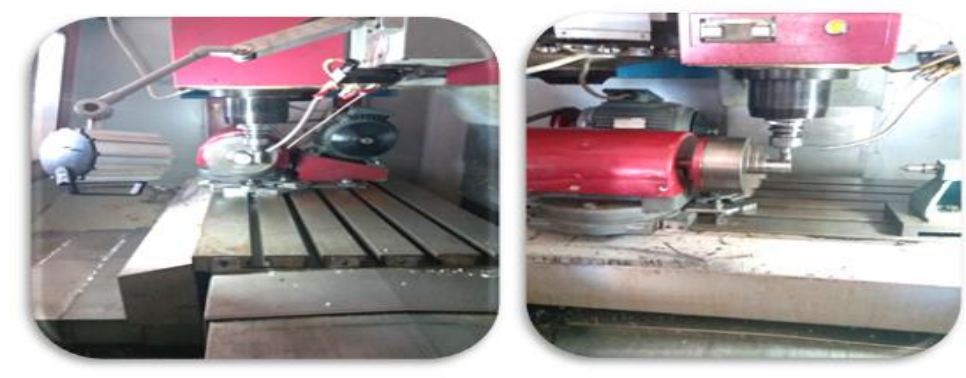

(a)
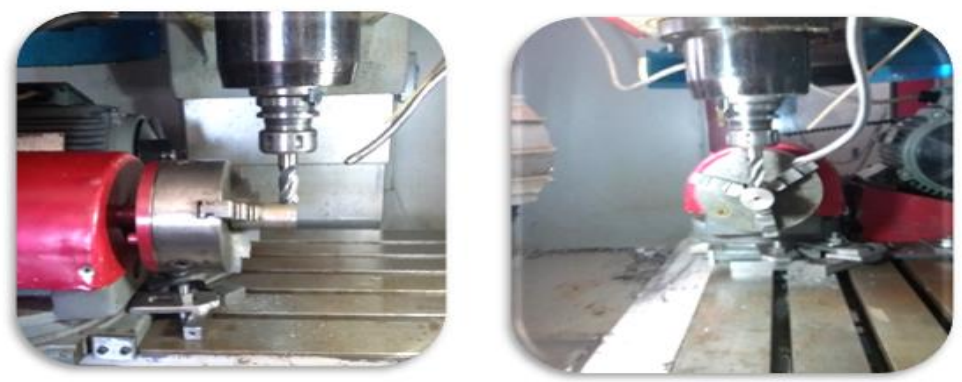

(b)

Şekil 2. (a) Teğetsel tornalama-frezeleme (b) Ortagonal tornalama-frezeleme Figure 2. (a) Tangential turning-milling (b) Orthogonal turning-milling 
Parametrelerin belirlenmesinde şunlar dikkate alınmıştır.

- İşleme yöntemi kesici takımın iş parçasına temas şekli Ortagonal ve teğetsel olarak tanımlanmıştır.

- Malzeme ve kesici takımın devri belirlenirken malzeme özelliklerine göre tablolardan ve tezgâhın özellikleri dikkate alınarak uygun değerler belirlenmiştir.

- Eksenel ilerleme hizı belirlenirken tezgâhın en küçük ilerleme hızı ve daha büyük ilerleme hızları dikkate alınmıştır.

- Talaş derinliği seviyeleri ise genellikle frezelemede kullanılan talaş derinliği seviyelerine göre belirlenmiştir.
Deneysel çalışmalar Tablo 4'de verilen parametre ve seviyeleri dikkate alınarak $\mathrm{L}_{36}$ ortagonal dizinine göre yapılmıştır. $\mathrm{L}_{36}$ ortagonal dizinine göre yapılan deneylerde ortalama yüzey pürüzlülüğü ölçümleri MİTUTOYO SJ-210 yüzey pürüzlülük cihazıyla yapılmıştır. Ölçümler silindirik iş parçası $\mathrm{V}$ yatağına yerleştirilerek, cihaz ISO 1997 standartlarına göre 0,5 mm/sn ölçme hızı ve 0,8 ölçüm katsayısına göre ayarlanarak yapılmıştır. Ölçümler iş parçası ekseni doğrultusunda ve işleme yönüne paralel olarak yapılmıştır. İşlenmiş yüzeyde silindirik parça her ölçümden sonra bir miktar döndürülerek 3 farklı noktadan ölçüm alınarak daha sonra bu ölçümlerin aritmetik ortalaması alınmıştır.

Tablo 3. Deneydeki parametreler ve seviyeleri

Table 3. Parameters and levels in the experiment

\begin{tabular}{lcccc}
\hline \multirow{2}{*}{ Parametreler } & Sembol & \multicolumn{3}{c}{ Seviyeleri } \\
\cline { 3 - 5 } & & Seviye 1 & Seviye 2 & Seviye 3 \\
\hline İşlem & $\mathrm{A}$ & 1 & 2 & \\
Kesici Takım Devri (dev/dak) & $\mathrm{B}$ & 250 & 350 & 450 \\
İş Parçası Devri (dev/dak) & $\mathrm{C}$ & 140 & 180 & 224 \\
Talaş Derinliği (mm) & $\mathrm{E}$ & 0.1 & 0.5 & 1.0 \\
Eksenel İlerleme Hızı (mm/dak $)$ & $\mathrm{D}$ & 3.2 & 7,9 & 12.6 \\
\hline
\end{tabular}

\section{Sonuç ve Tartışma}

Tornalama-frezeleme yöntemleri iş parçasının ve kesici takımın hareket şekilleri ve birbirine temas durumlarına göre farklılıklar göstermekte ve elde edilen yüzey kaliteleri de değişkenlik göstermektedir. Ayrıca yüzey kalitesine etki eden kesme parametreleri de tornalama ve frezeleme yöntemlerinde etkili olan parametrelerdir. Tornalamada iş parçasının dönme hareketinden dolayı iş parçasının devri önemli bir faktördür. Frezeleme işleminde ise kesici takım devri etkili parametrelerin başında gelmektedir. Frezeleme ve tornalama işlemlerinde talaş kaldırma işleminin gerçekleşmesi için eksenel ilerleme hareketinin ve talaş derinliğinin verilmesi gerekmektedir. Tornalama-frezeleme yönteminde bu parametrelerin yanı sıra kesici takım ile iş parçasının temas şekli de elde edilen yüzey formları ve yüzey kalitesi üzerinde ciddi bir etkiye sahiptir. Tablo 4 ve Şekil 3'te belirtilen bu kesme parametrelerinin ortalama yüzey pürüzlülüğü üzerindeki etkileri Taguchi deney tasarım metodunda $\mathrm{L}_{36}$ ortagonal dizinine göre yapılan deneyler verilmiştir. Şekil 3'te kesme parametrelerinin yüzey pürüzlülügü üzerindeki etkileri toplu bir şekilde gösterilmektedir. Şekil 3 incelendiğinde işlem parametresinde kullanılan teğetsel temas şeklinin ortagonal temas şekline göre yüzey pürüzlülügünü çok önemli bir oranda azalttığı görülmektedir. Ratnam ve diğ. Yapmış olduğu çalışmada teğetsel temas şeklinin ortagonal temas şekline göre takım titreşimini azalttığını ve oluşan yüzey pürüzlülüğü değerinin daha az olduğunu belirtmişlerdir [10]. Kesici takım ve iş parçası devirlerinin ikinci seviyelerine kadar arttırılmasında yüzey pürüzlülügüunün azaldığı, bu değerin üzerindeki artışlarda ise arttığı görülmektedir. Talaş derinliğgi 
ve eksenel kesme parametrelerinin artırılmasında yüzey pürüzlülüğünün arttığı görülmektedir. Babu ve diğ. Yapmış olduğu çalışmalarda kesme parametrelerinin benzer etkiler gösterdiğini belirtmişlerdir[16].

Tablo 4. L36 ortagonal dizine göre elde edilen deney sonuçlart

Table 4. Test results obtained according to L36 orthogonal index

\begin{tabular}{|c|c|c|c|c|c|c|}
\hline $\begin{array}{c}\text { Deney } \\
\text { No }\end{array}$ & İşlem & $\begin{array}{c}\text { Kesici } \\
\text { Takım } \\
\text { Devri } \\
\text { (dev/dk) }\end{array}$ & $\begin{array}{c}\text { İş Parçası } \\
\text { Devri } \\
\text { (dev/dak) }\end{array}$ & $\begin{array}{l}\text { Talaş } \\
\text { Derinliği } \\
(\mathbf{m m})\end{array}$ & $\begin{array}{c}\text { Eksenel } \\
\text { İlerleme } \\
\text { Hizl } \\
(\mathbf{m m} / \text { dak }) \\
\end{array}$ & $\begin{array}{l}\text { Ort. Yüzey } \\
\text { Pürüzlülüğüu } \\
\quad(\mu \mathrm{m})\end{array}$ \\
\hline 1 & 1 & 250 & 140 & 0,1 & 3,2 & 3,243 \\
\hline 2 & 1 & 350 & 180 & 0,5 & 7,9 & 1,928 \\
\hline 3 & 1 & 450 & 224 & 1,0 & 12,6 & 3,847 \\
\hline 4 & 1 & 250 & 140 & 0,1 & 3,2 & 3,214 \\
\hline 5 & 1 & 350 & 180 & 0,5 & 7,9 & 1,947 \\
\hline 6 & 1 & 450 & 224 & 1,0 & 12,6 & 3,791 \\
\hline 7 & 1 & 250 & 140 & 0,5 & 12,6 & 3,342 \\
\hline 8 & 1 & 350 & 180 & 1,0 & 3,2 & 1,822 \\
\hline 9 & 1 & 450 & 224 & 0,1 & 7,9 & 3,530 \\
\hline 10 & 1 & 250 & 140 & 1,0 & 7,9 & 3,311 \\
\hline 11 & 1 & 350 & 180 & 0,1 & 12,6 & 2,144 \\
\hline 12 & 1 & 450 & 224 & 0,5 & 3,2 & 2,642 \\
\hline 13 & 1 & 250 & 180 & 1,0 & 3,2 & 2,714 \\
\hline 14 & 1 & 350 & 224 & 0,1 & 7,9 & 2,453 \\
\hline 15 & 1 & 450 & 140 & 0,5 & 12,6 & 3,572 \\
\hline 16 & 1 & 250 & 180 & 1,0 & 7,9 & 2,725 \\
\hline 17 & 1 & 350 & 224 & 0,1 & 12,6 & 2,681 \\
\hline 18 & 1 & 450 & 140 & 0,5 & 3,2 & 3,420 \\
\hline 19 & 2 & 250 & 180 & 0,1 & 12,6 & 1,034 \\
\hline 20 & 2 & 350 & 224 & 0,5 & 3,2 & 1,109 \\
\hline 21 & 2 & 450 & 140 & 1,0 & 7,9 & 1,650 \\
\hline 22 & 2 & 250 & 180 & 0,5 & 12,6 & 1,180 \\
\hline 23 & 2 & 350 & 224 & 1,0 & 3,2 & 1,258 \\
\hline 24 & 2 & 450 & 140 & 0,1 & 7,9 & 1,274 \\
\hline 25 & 2 & 250 & 224 & 0,5 & 3,2 & 1,240 \\
\hline 26 & 2 & 350 & 140 & 1,0 & 7,9 & 1,579 \\
\hline 27 & 2 & 450 & 180 & 0,1 & 12,6 & 0,966 \\
\hline 28 & 2 & 250 & 224 & 0,5 & 7,9 & 1,663 \\
\hline 29 & 2 & 350 & 140 & 1,0 & 12,6 & 1,820 \\
\hline 30 & 2 & 450 & 180 & 0,1 & 3,2 & 0,625 \\
\hline 31 & 2 & 250 & 224 & 1,0 & 12,6 & 2,174 \\
\hline 32 & 2 & 350 & 140 & 0,1 & 3,2 & 0,909 \\
\hline 33 & 2 & 450 & 180 & 0,5 & 7,9 & 0,957 \\
\hline 34 & 2 & 250 & 224 & 0,1 & 7,9 & 1,457 \\
\hline 35 & 2 & 350 & 140 & 0,5 & 12,6 & 1,604 \\
\hline 36 & 2 & 450 & 180 & 1,0 & 3,2 & 0,809 \\
\hline
\end{tabular}




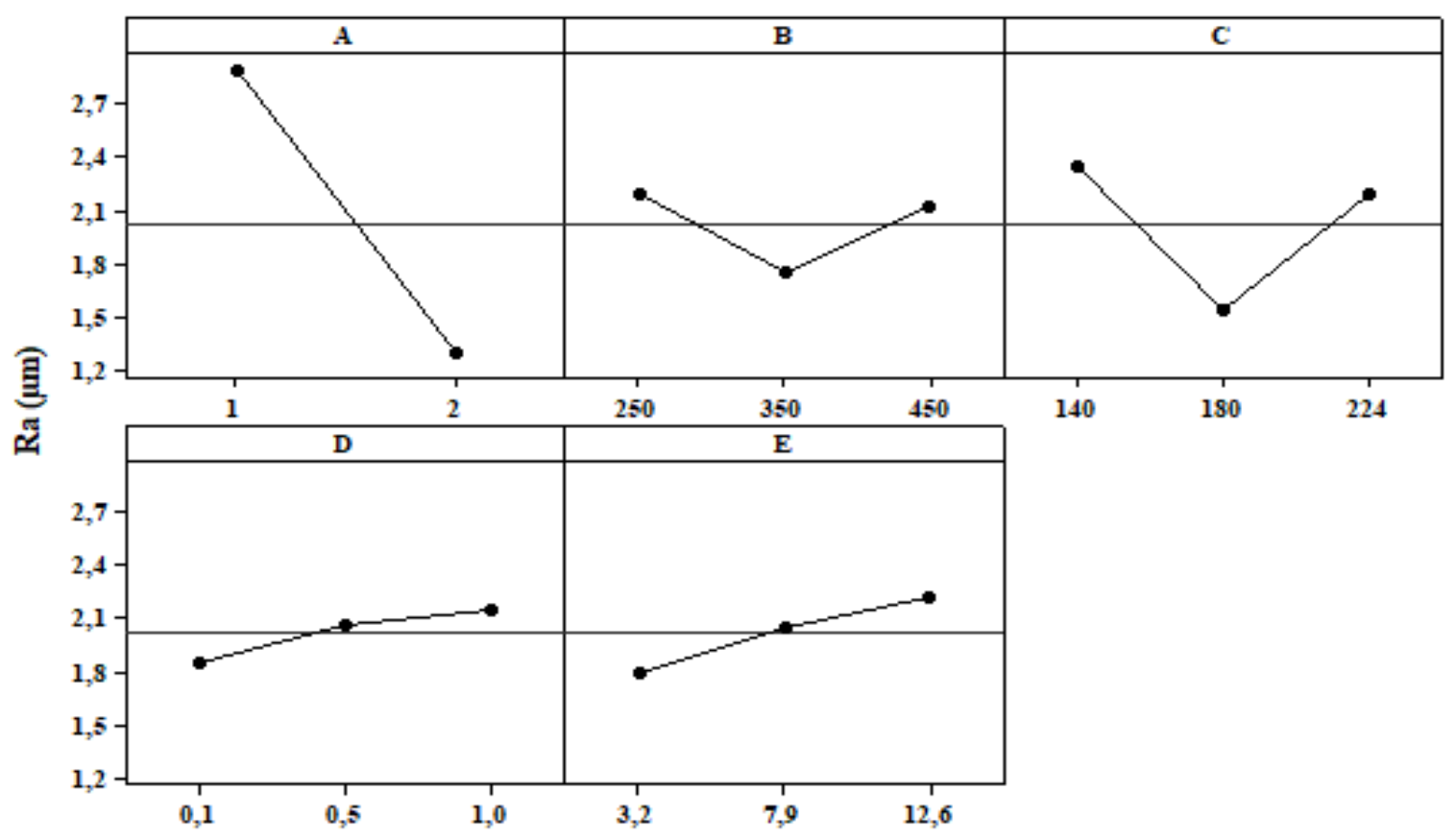

Şekil 3. Işleme parametrelerinin ortalama yüzey pürüzlülüğüne etkisi

Figure 3. Effect of machining parameters on average surface roughness

Şekil 4 incelendiğinde işleme parametresinin yüzey pürüzlülüğü üzerinde önemli bir etkiye sahip olduğu görülmektedir. İşleme parametresinde birinci seviye kesici takım iş parçasına ortagonal olarak temas ettirilerek talaş kaldırmakta ve kesici takımın alın yüzeyindeki ağızları talaş kaldırma işlemini gerçekleştirmektedir. Kesme şekli kesintili bir kesme işlemi olduğundan oluşan yüzey pürüzlülüğü değeri yüksek çıkmaktadır. İşleme parametresinin ikinci seviyesinde ise kesici takım iş parçasına teğetsel olarak temas ettirilmekte ve kesici takımın çevresel kesici ağızları kesme yapmaktadır. Kesme işleminde kesici takım iş parçası ile sürekli temas halinde olmasından dolayı kesici takım da oluşan titreşimler ortagonal kesme işlemine göre daha az olmasından dolayı elde edilen yüzey pürüzlülüğü değeri düşük olmaktadır.

Şekil 4 ve 5 incelendiğinde kesici takım devrinin ikinci seviyesine kadar olan artışlarda yüzey pürüzlülüğünün azaldığı bu değerin üzerindeki devir artışlarında ise yüzey pürüzlülüğünün arttığ1 görülmektedir. Uygun kesici takım devri işlenen iş parçası malzemesi, kesici takım malzemesi işleme yöntemi kesici takım çapı faktörleri dikkate alınarak aşağıdaki Denklem
1 'den elde edilir. Kesici takım devrinin bu denkleme uygun değeri ikinci seviye değerine denk gelmektedir. Yüzey pürüzlülüğü bu değere yaklaştıkça azalmakta bu değerden uzaklaştıkça kötüleşmektedir. Şekil 5 incelendiğinde talaş derinliğinin artması ile yüzey pürüzlülüğünün arttığı görülmektedir. Talaş derinliği arttıkça iş parçasından kaldırılan talaş miktarı artmakta, gerekli olan kesme kuvveti artışına bağlı olarak titreşim ve yüzey pürüzlülüğünün arttığı ifade edilebilir.

Şekil 6'da iş parçası devri ve eksenel ilerleme hızı parametrelerinin yüzey pürüzlülüğü üzerindeki etkisi görülmektedir. İş parçası devrinin ikinci seviyesine kadarki, artışlarda yüzey pürüzlülüğünün azaldığı bu değerden uzaklaştıkça yüzey pürüzlülüğü değerinin arttığ 1 görülmektedir. Tornalama-frezeleme yöntemleri, tornalama ve frezeleme yöntemlerinin bir kombinasyonu olduğundan uygun iş parças1 devri de tornalama işlemindeki Denklem 1 de verilen kesme hı formülünden hesaplanmaktadır. Şekil 6 incelendiğinde de seviye ikide verilen değerden uzaklaştıkça yüzey pürüzlülüğünün arttığ görülmektedir. Eksenel ilerleme hızının artması ile birim zamanda kaldırılacak talaş miktarının artması yüzey 
pürüzlülüğü değerini arttırmaktadır. Denklem 1 'de;

$V=\frac{\pi \cdot D \cdot N}{1000} \quad\left(\frac{m}{d a k}\right)$

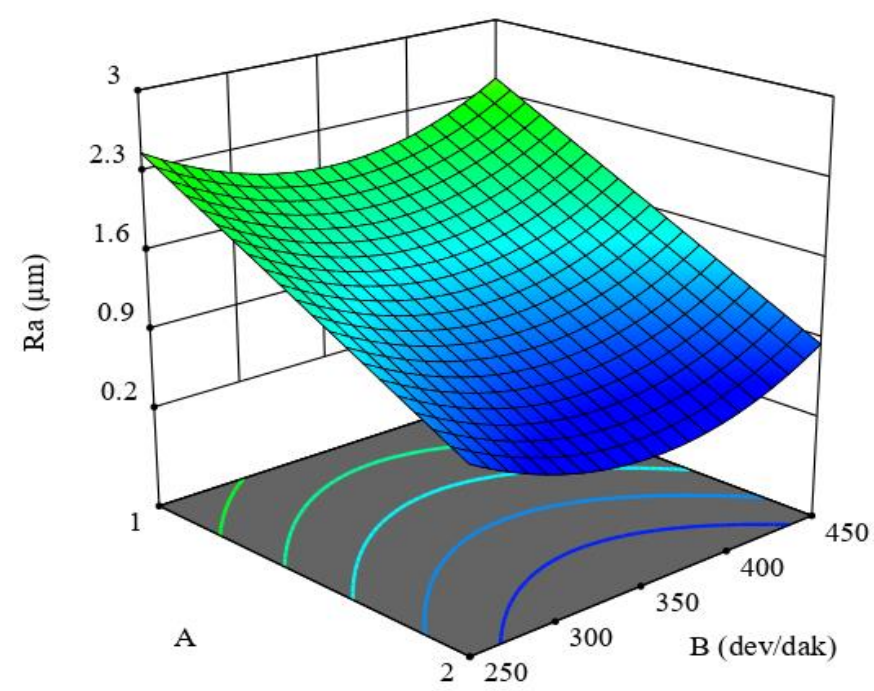

Şekil 4. Işsleme yöntemi ve kesici takım devrinin yüzey pürüzlülüğ̈̈ üzerindeki etkisi

Figure 4. Processing method and the effect of cutting tool speed on surface roughness
$V$, kesme hızını, D, iş parçası veya kesici takım çapını, $N$, ise iş parçası veya kesici takım devrini ifade etmektedir.

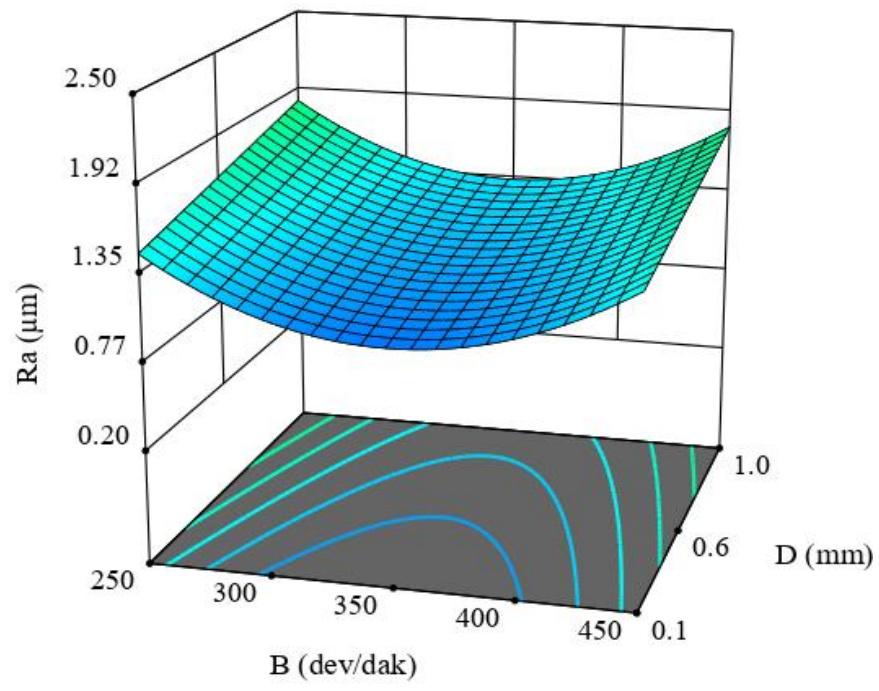

Şekil 5. Talaş Derinliği ve iş parçası devrinin yüzey pürüzlülüğ̈̈ üzerindeki etkisi

Figure 5. Effect of workpiece revolution and depth of cut on surface roughness

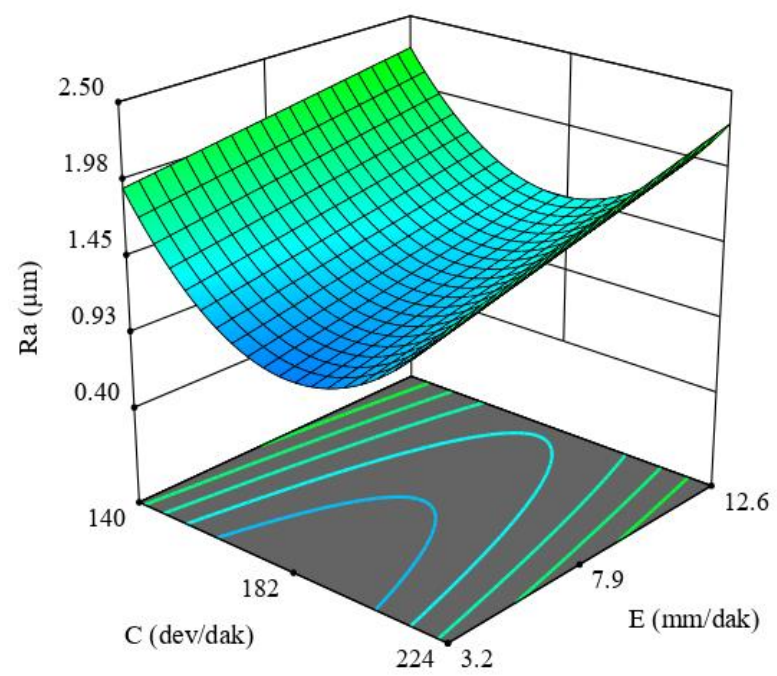

Şekil 6. İş parçası devrinin ve Eksenel ilerleme hızının yüzey pürüzlülüğ̈̈ üzerindeki etkisi Figure 6. Effect of workpiece revolution and axial feed rate on surface roughness 
Şekil 7 incelendiğinde $\mathrm{L}_{36}$ ortagonal dizine göre yapılan deneylerden elde edilen yüzey pürüzlülüğü değerleri "En Küçük En İyi" performans karakteristiğine göre hesaplanarak $\mathrm{S} / \mathrm{N}$ oranlarına dönüştürüldüğü ve bu parametrelerde minimum yüzey pürüzlülüğü için optimum seviyeler görülmektedir. Her parametre için optimum yüzey pürüzlülüğü değerini, $\mathrm{S} / \mathrm{N}$ oranın en yüksek değerindeki seviyesi vermektedir. Yüzey pürüzlülüğünün minimum değeri için optimum parametre seviyeleri A2B2C2D1E1 şeklindedir. Tablo 5 'te ANOVA varyans analizi incelendiğinde parametrelerin yüzey pürüzlülügü üzerinde etkili olduğu görülmektedir. İşleme parametresinin diğer parametrelere göre yüzey pürüzlülüğü üzerinde çok daha fazla etkili olduğu görülmektedir.

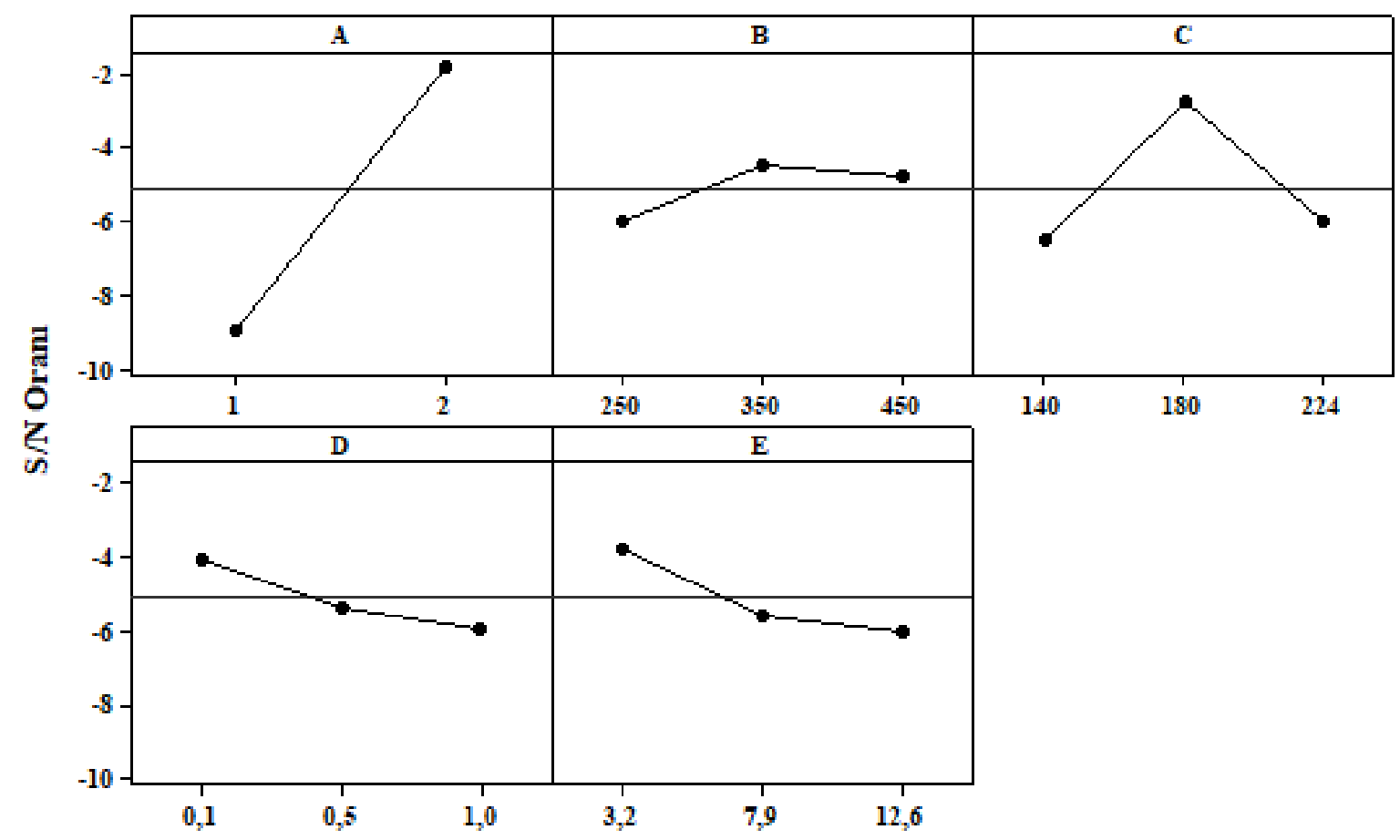

S/N: En Küçük En İyi

Şekil 7. Issleme parametrelerinin S/N oranina etkisi

Figure 7. Effect of machining parameters on $S / N$ ratio

Tablo 5. AISI 1040 çeliğinin işlenmesinde ortalama yüzey pürüzlülü̈̆̈̈nün ANOVA analizi Table 5. ANOVA analysis of average surface roughness in the processing of AISI 1040 steel

\begin{tabular}{lccccc}
\hline \multicolumn{1}{c}{ Parametreler } & $\begin{array}{c}\text { Serbestlik } \\
\text { Derecesi }\end{array}$ & $\begin{array}{c}\text { Kareler } \\
\text { Toplamı }\end{array}$ & Varyans & F Değeri & $\begin{array}{c}\text { \% } \\
\text { Dağılımı }\end{array}$ \\
\hline İşlem & 1 & 465,8483 & 465,8483 & 463,6539 & 69,40766 \\
Kesici takım devri & 2 & 19,62478 & 9,812388 & 9,766166 & 2,630213 \\
İş parçası devri & 2 & 109,2044 & 54,60219 & 54,34498 & 16,0057 \\
Talaş derinliği & 2 & 20,12669 & 10,06335 & 10,01594 & 2,705156 \\
Eksenel ilerleme & 2 & 28,80225 & 14,40113 & 14,33329 & 4,000539 \\
Hata & 26 & 26,12305 & 1,004733 & 0 & 5,250725 \\
& & 669,7295 & & & 100 \\
\hline \multicolumn{1}{c}{ TOPLAM } & & & & &
\end{tabular}


Kesme parametrelerinin yüzey pürüzlülüğg̈ üzerindeki etkilerinin belirlenmesi ve matematiksel modelinin oluşturulması için Minitab 15 paket programında yanıt yüzey yöntemi kullanilarak Denklem 2 oluşturulmuştur. İkinci derece olarak oluşturulan denklemin uygunluk değeri $\mathrm{R}^{2}=0,95$ olarak belirlenmiştir. Goal programında yanıt yüzey yöntemi kullanılarak oluşturulmuş, Denklem 2 uygunluk denklemi olarak belirlenmiştir. Sınırlayıcı olarak parametrelerin en küçük ve en büyük değerleri seçilmiştir. Genetik algoritma yöntemi ile yapılan optimizasyon işleminde uygunluk denklemi ve sinırlayıcıların belirlenmesi gerekir. Ayrica algoritma ait iterasyon sayısı, popülasyon sayısı, çaprazlama tipi, çaprazlama olasılığı, mutasyon oranı gibi değerler önem arz etmektedir. Bu çalışmada iterasyon sayıs1 1000, popülasyon sayıs 100, çaprazlama tipi iki noktadan çaprazlama, çaprazlama olasılığı 0,95 , mutasyon oranı ise 0,005 seçilmiştir. Genetik algoritma yöntemi ile yapılan optimizasyon işleminde elde edilen sonuçlar, $\mathrm{S} / \mathrm{N}$ oranlarına göre belirlenen optimun sonuçlar ve yanıt yüzey yöntemi ile elde edilen sonuçlar Tablo 6'da verilmiștir. Sonuçlar incelendiğinde bulunan minimum yüzey pürüzlülüğü değerlerinin ve bu değerleri veren parametrelerin birbiri ile uyumlu olduğu görülmektedir.

Denklem;

$R a=23.60868-1.64593 * A-0.02275 * B-0.17114 * C+$ $0.4928 * D+0.0553 * E+0.0000375 * B^{2}+0.00047 * C^{2}$

Tablo 6. AISI 1040 çeliğinin işlenmesinde yüzey pürüzlülüğ̈̈nün optimizasyon değerleri Table 6. Optimization values of surface roughness in the processing of AISI 1040 steel

\begin{tabular}{ccccccc}
\hline & \multicolumn{3}{c}{ Parametreler } & & Sonuç \\
\hline Optimizasyon yöntemi & A & B & C & D & E & Ra \\
S/N oranı & 2 & 350 & 180 & 0,1 & 3,2 & 0,667552 \\
& 2 & 350 & 180 & 0,1 & 3,2 & 0,660115 \\
Yanıt Yüzey Metodu & 2 & & & & \\
Genetik Algoritma & 2 & 379,1233 & 182,20662 & 0,10018 & 3,2058 & 0,6523 \\
\hline
\end{tabular}

\section{Sonuçlar}

Bu çalışmada AISI 1040 malzemesi ortagonal ve teğetsel tornalama-frezeleme yöntemleri ile işlenmesinde kesme parametrelerinin yüzey pürüzlülüğü üzerindeki etkileri incelenmiştir. Deneysel çalışma planı Taguchi deney tasarım yönteminde $\mathrm{L}_{36}$ ortagonal dizinine göre seçilmiștir. Deneysel çalıșmalarda ișleme parametreleri olarak; işlem, kesici takım devri, iş parçası devri, talaş derinliği ve eksenel ilerleme hızı parametreleri seçilmiştir. Deneysel çalışma sonuçları Minitab15 paket programı kullanılarak $\mathrm{S} / \mathrm{N}$ oranlarına dönüştürülüp optimum kesme parametreleri belirlenmiştir. ANOVA varyans analizi ile de istatistiksel olarak analiz edilmiştir. Yanıt yüzey yöntemi ile yüzey pürüzlülüğünün kesme parametrelerine bağlı olarak matematiksel modeli oluşturulmuştur. Ayrıca genetik algoritma yöntemi kullanılarak minimum yüzey pürüzlülüğü için en uygun kesme parametre değerleri belirlenmiştir. Yapılan deneysel çalışmalar ve incelemelerde şu sonuçlar elde edilmiştir;

$\checkmark$ İşleme yöntemlerinin yüzey pürüzlülüğü değeri üzerinde \%69 etkili olduğu, teğetsel tornalama-frezeleme yönteminin ortagonal tornalama-frezeleme yöntemine göre yüzey 
pürüzlülüğü değerini çok fazla düşürdüğü tespit edilmiştir.

$\checkmark$ İş parçası devri ve kesici takım devri parametrelerinin belirli bir değere kadar arttırılması ile yüzey pürüzlülüğü değerinin düştüğü bu değerden sonraki değerlerde ise yüzey pürüzlülüğü değerini yükselttiği belirlenmiştir.

$\checkmark$ Talaş derinliği ve eksenel ilerleme hızı parametre değerlerinin artması ile yüzey pürüzlülüğü değerinin $\operatorname{artt1ğ}$ tespit edilmiştir.

$\checkmark$ S/N oranları incelendiğinde işleme parametrelerinin $\quad$ A2B2C2D1E1 seviyelerinin yüzey pürüzlülüğü değerinin en iyi sonucu verdiği görülmüştür.

$\checkmark$ Varyans analizi incelendiğinde yüzey pürüzlülüğü üzerinde işleme parametresinin en büyük etkiye sahip olduğu görülmüştür.

$\checkmark$ Yanıt yüzey yöntemi ile elde edilen matematiksel modelin \%95 deney sonuçları ile uyumlu olduğu tespit edilmiştir.

$\checkmark$ Genetik algoritma yöntemi, S/N oranları ve matematiksel modelden elde edilen optimum yüzey pürüzlülüğü değerlerinin birbirine çok yakın olduğu tespit edilmiştir.

\section{Kaynaklar}

[1] Kopac J, Pogacink M., (1997). Theory and practice of achieving quality surface in turn milling. Int. J. Mach Tools Manuf, 37,5 (709-715).

[2] Pogacink M, Kopac J., (2000). Dynamic stabilization of the turnmilling process by parameter optimization. Proc Inst Mech Eng, 214 (127-135).

[3] Pogacnik M. ve Kopac J., (1997). Dynamic stabilization of the turn-milling process by parameter optimization" Proceedings of the institution of mechanical engineers, 214 (127-135).

[4] Kopac J. ve Pogacnik M., (1997). Theory and Practice of Achieving Quality surface in turn milling Int. J. Mach. Tools Manufct., 37,5 (709-715).

[5] Choudhury, S.K. ve Bajpai, J.B., (2005). Investigation in orthogonal turn-milling towards beter surface finish, Journal of Materials Processing Technology, 170 (487-493).

[6] Savas V., Ozay C., (2008). The optimization of the surface roughness in the process of tangential Turnmilling using genetic algorithm, Int. J. Adv. Manuf. Technol., 37 (335-340).

[7] Savas V., Ozay C., (2007). Analysis of the surface roughness of tangential turn-milling for machining with end milling cutter, Journal of Materials Processing Technology, 186 (279-283).
[8] Lee, Y.S., Chiou, C.J., (1999). Unfolded projection approach to machining non-coaxial parts on mill-turn machines, Computers in Industry 39 (147-173).

[9] Kara güzel U., Uysal E., Budak, E., Bakkal M., (2015). Analytical modeling of turn-milling process geometry, kinematics and mechanics, International Journal of Machine Tools and Manufacture, 91 (2433).

[10] Ratnam, Ch., Arun Vikram, K., Ben, B.S., Murthy, B.S.N., (2016). Process monitoring and effects of process parameters on responses in turnmilling operations based on SN ratio and ANOVA, Measurement 94 (221-232).

[11] Kilıçkap,E., Hüseyinoğlu, M., (2010) Tepki yüzey modeli ve genetik algoritma kullanılarak AISI 316' nın delinmesinde oluşan çapak yüksekliğinin modellenmesi ve optimizasyonu, Dicle Üniversitesi Mühendislik Fakültesi Mühendislik Dergisi 1,1 ( $71-80)$.

[12] Senthilkumar D, Rajendran I., (2012). Optimization of deep cryogenic treatment to reduce wear loss of 4140 steel, Materials and Manufacturing Processes, 27,5 (567-572).

[13] Murat, D., Ensarioğlu, C., Gürsakal, N., Oral, A., Çakır, M. C., (2018). Evaluation of tool wear for hard turning operations through response surface methodology, Journal of the Faculty of Engineering and Architecture of Gazi University 33,4 (12991308).

[14] Savas V. Ozay C., (2016). Ballikaya H. Experimental investigation of cutting parameters in machining of $100 \mathrm{Cr} 6$ with tangential turn-milling method, Adv. Manuf., 4,1 (97-104),

[15] Yağmur S., Çakıroğlu R. Acır A. Şeker U., (2017). AISI 1050 çeliğinin delinmesinde kesme kuvvetlerinin taguchi metodu ile optimizasyonu, Gazi Üniversitesi Fen Bilimleri Dergisi Part C: Tasarım ve Teknoloji, 5,2 241-246,

[16] Babu G.P., Murthy B., Rao K.V., Kumar K.A., (2017). Taguchi based optimization of process parameters in orthogonal turn milling of ASTM B139, 5th International Conference of Materials Processing and Characterization, Materials Today: Proceedings 4 (2147-2156) 